\title{
Autophagy Activation by Rapamycin Before Hypoxia-Reoxygenation Reduces Endoplasmic Reticulum Stress in Alveolar Epithelial Cells
}

\author{
Tao Fan ${ }^{\mathrm{a}}$ Lei Chen ${ }^{\mathrm{a}}$ Zhixin Huang ${ }^{\mathrm{b}}$ Wei Wang ${ }^{\mathrm{a}}$ Boyou Zhang ${ }^{\mathrm{a}}$ Yao Xu \\ Zhangfan $\mathrm{Mao}^{\mathrm{a}} \mathrm{Hao} \mathrm{Hu}^{\mathrm{a}}$ Qing Genga

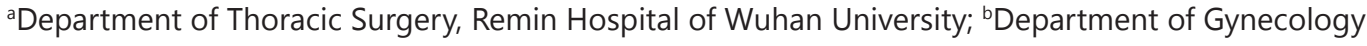 \\ and Obstetrics, Remin Hospital of Wuhan University, Wuhan, China
}

\section{Key Words}

Autophagy - Unfolded protein response - Endoplasmatic reticulum stress - Rapamycin • Alveolar hypoxia-reoxygenation

\begin{abstract}
Background: To determine potential effects of autophagy activation on hypoxia-reoxygenation $(H / R)$ induced damage of a rat alveolar epithelial cell line. Methods: CCL149 cells were subjected to autophagy agonist (rapamycin, Rap), autophagy inhibitor (3-methyladenine, 3-MA) or PBS for $1 \mathrm{~h}$ before H/R treatment for $2 \mathrm{~h}, 4 \mathrm{~h}$ and $6 \mathrm{~h}$. The optimal concentration of Rap (150 nM, $200 \mathrm{nM}$ and $250 \mathrm{nM})$ or 3-MA (5 mM, $10 \mathrm{mM}$ and $15 \mathrm{mM}$ ) was obtained from MTT assay. Autophagy was determined by fluorescence microscopy of eRFP-LC3 positive cells, transmission electron microscopy of autophagosome, western blot of LC3, AMPK, Beclin-1, HDAC6 and p62 proteins. Endoplasmatic reticulum stress was indicated by detecting expressions of BIP, XBP-1 and CHOP via western blot. Results: Rap at concentration of 250 $\mathrm{nM}$ before H/R increased the autophagy formation with more eRFP-LC3 positive cells and higher expressions of LC3-II, Beclin-1, HDAC6 and p62, but lower expressions of BIP, XBP-1 and CHOP in H/R treated CCL149. This effect seemed to be still obvious after H/R exposure for 6 h. The contrary results were obtained by treatment with 5 mM 3-MA. Conclusion: Rap might be a promising agent before mechanical ventilation or reperfusion to prevent re-damage in hypoxia related lung diseases.

\section{Introduction}

Alveolar hypoxia is a common condition occurred at high altitude, during lung transplantation due to ischemia and in various lung diseases, including chronic obstructive pulmonary disease (COPD), pulmonary fibrosis, pulmonary artery hypertension and T. Fan and L. Chen contributed equally to this work. 
pulmonary edema resulting from acute lung injury or congestive heart failure [1-3]. Subsequent reoxygenation by mechanical ventilation and/or reperfusion is the direct approach to restore the physiologic and pathologic conditions. However, several studies have indicated that hypoxia-reoxygenation (H/R) usually contributes to reactive oxygen species (ROS) production [4] which then initiates uncontrolled oxidative stress [5] and the subsequent cell apoptosis with dysfunctional organelles [such as endoplasmatic reticulum (ER) in which protein-folding capacity was altered and amounts of unfolded/misfolded proteins were accumulated in the lumen, that is ER stress]. [6] The above alterations may further exacerbate lung injury [4]. Thus, exploring the effective strategies to prevent $H / R$ induced lung injuries has been a hot issue $[7,8]$.

Recent studies suggest that cells may develop a self-protective signal transduction pathway termed the unfolded protein response (UPR) in response to the ER stress, in which five mechanisms are included: [6, 9] (i) suppression of protein synthesis through phosphorylation of eukaryotic translation initiation factor 2 subunit a (elf2a) by PKR-like ER kinase (PERK) to prevent further protein accumulation; (ii) transcriptional induction of ER chaperone genes [such as glucoseregulated protein 78 (GRP78/BIP)] by activating transcription factor-6 (ATF-6) to enhance folding capacity; (iii) transcriptional induction of ER-associated degradation (ERAD) genes via X-box binding protein-1 (XBP1) which was the processed product of ATF- 6 by the inositol-requiring enzyme 1 (IRE1) in order to increase ERAD capacity; (iv) transcriptional induction of apoptotic genes [such as CHOP (C/EBP homologous protein, growth arrest and DNA damage inducible gene 153, GADD153)] by ATF6 or activating transcription factor 4 (ATF-4) to remove stressed cells; and (v) transcriptional activation of the components of the autophagy machinery [microtubule-associated protein 1 light chain 3 (LC3), autophagy-related genes (ATGs)] by ATF4 when the amount of unfolded/ misfolded proteins exceeds the capacity of the proteasome-mediated degradation system. [10] Furthermore, several studies imply that the first four mechanisms of UPR are required for ER stress-induced autophagy in mammalian cells [11-13] to sequester damaged organelles/ proteins in autophagosomes and allow the recycling of their breakdown products aiming to help the cell survive in the adverse conditions [9]. Therefore, we speculate over-activation of autophagy before H/R may be beneficial for feedback reduction of the UPR response and alleviation of H/R induced ER stress, ultimately improving the tissue injuries. Our hypothesis has been demonstrated by some studies. For example, Sheng et al. [14] report that the use of the autophagy-stimulating agent rapamycin (Rap) in vitro and in vivo $24 \mathrm{~h}$ before the onset of lethal ischemia reduces ER stress and hypoxia-induced neuronal damage. Similarly, Carloni et al. [15] show that UPR is strongly activated after neonatal hypoxia/ischemia and overactivation of autophagy with Rap significantly reduces the necessity of this response, while the specific autophagosome formation inhibitor 3-methyladenine (3-MA) administered after Rap treatment completely reverses the above protective mechanism, promoting the cell apoptosis [15, 16]. Guan et al. [17] also confirmed the protective role of Rap, but the deteriorative impact of 3-MA on renal tissue damage during ischemia/reperfusion (I/R) in vivo and tubular cell apoptosis during H/R in vitro. However, no study has investigated the effects of autophagy activation and inhibition on ER stress and UPR response in pulmonary epithelial cells undergoing $\mathrm{H} / \mathrm{R}$, which was the goal of this present study.

In this study, the representative alveolar epithelial cell line CCL149 [18] was used to undergo the addition of 3-MA or Rap prior to H/R treatment for different time points. We aimed to preliminarily observe whether the expressions of autophagy related genes [LC3, 5 '-adenosine monophosphate (AMP)-activated protein kinase (AMPK), Beclin-1, histone deacetylase 6 (HDAC6) and p62] were increased in cells under H/R and/or Rap treatment but decreased after 3-MA treatment, as well as the contrary results of other UPR genes (BIP, XBP- 1 and CHOP) under the above treatments. This study may provide a promising approach for prevention and treatment of $\mathrm{H} / \mathrm{R}$ induced lung injuries. 


\section{Cellular Physiology Cell Physiol Biochem 2017;41:79-90 \begin{tabular}{ll|l} 
and Biochemistry Publisned onIIne: January 17, 2017 & $\begin{array}{l}\text { C } 2017 \text { The Author(s). Published by S. Karger AG, Basel } \\
\text { www.karger.com/cpb }\end{array}$ \\
\hline
\end{tabular}}

Fan et al.: Autophagy Activation for Hypoxia Related Lung Diseases

\section{Materials and Methods}

\section{Cell culture}

Rat alveolar epithelial cell line (ATCC, Manassas, VA, \#CCL149) was cultured in F-12K medium (ATCC, Manassas, VA, \#30-2004) supplemented with 20\% fetal bovine serum (FBS, Invitrogen, Carlsbad, CA, \#26400044) at $37^{\circ} \mathrm{C}$ in a humidified $5 \% \mathrm{CO}_{2}$ atmosphere. CCL149 cells at a confluence of $80 \%$ were digested with $0.25 \%$ trypsin for subculture.

\section{Establishment of stable eRFP-LC3/CCL149 cells}

For establishing CCL149 eRFP-LC3, cells were transfected with eRFP-LC3 plasmid (Addgene, Cambridge MA, USA, \#21073) using Lipofectamine 2000 reagent (Invitrogen, Carlsbad, CA, USA, \#11668027) according to the instructions of the manufacturer. After transfection for $24 \mathrm{~h}$, cells were transferred to a new plate and underwent selection in F-12K medium containing $300 \mu \mathrm{g} / \mathrm{ml}$ of G418 (Invitrogen, Carlsbad, CA, \#10131027). About 2 weeks post-transfection and expansion, cell colonies exhibiting strong red fluorescence were selected under a fluorescence microscope (Olympus, Tokyo, Japan) and then maintained in F-12K medium supplemented with $10 \% \mathrm{FBS}$ and $100 \mu \mathrm{g} / \mathrm{ml} \mathrm{G418}$ at $37^{\circ} \mathrm{C}$ and $5 \% \mathrm{CO}_{2}$.

\section{Cell viability assay}

The cytotoxicity of 3-MA and Rap against eRFP-LC3/CCL149 cells was determined by the 3-(4,5-dimethylthiazol-2-yl)-2,5-diphenyltetrazolium bromide (MTT). Briefly, $100 \mu \mathrm{l}$ of eRFP-LC3/CCL149 cells at a density of $2 \times 10^{4} / \mathrm{ml}$ were seeded into a 96-well plate and incubated overnight at $37^{\circ} \mathrm{C}$. After that, cells were treated in quintuplicate with Rap $(150 \mathrm{nM}, 200 \mathrm{nM}$ and $250 \mathrm{nM}$; diluted in DMSO; Alexis Biochemicals, Loerrach, Germany, \#380-004-M001) or 3-MA (5 mM, 10 mM and 15 mM; Sigma, USA, \#M9281) for 48 h. Untreated cells were used as controls. Cells in each well were added with $50 \mu$ l MTT ( $1 \mathrm{mg} / \mathrm{ml}$; Sigma, USA, \#M2128) and incubated for $4 \mathrm{~h}$. The formazan crystals were then solubilized by DMSO (150 $\mu$ l; Sigma, USA, \#D2650) and the absorbance was read at $570 \mathrm{~nm}$ using a microplate reader (Multiskan MK3, Thermo, USA). The cell inhibition rate (\%) at each concentration was calculated relative to controls from which the appropriate concentrations of Rap and 3-MA were selected for the following experiments.

\section{Drug administration}

eRFP-LC3/CCL149 cells were randomly divided into Rap, 3-MA and control groups in which the cells were respectively incubated with Rap, 3-MA (the optimal concentration obtained from MTT) or an equal volume of phosphate-buffered saline (PBS) for $1 \mathrm{~h}$ before the H/R treatment for $2 \mathrm{~h}, 4 \mathrm{~h}$ and $6 \mathrm{~h}$. H/R treatment was performed as previously described: [19] for hypoxia treatment, plated eRFP-LC3/CCL149 cells were placed in a humidified hypoxia chamber with $0.5 \%$ oxygen for a specified time course $(2 \mathrm{~h}, 4 \mathrm{~h}$ or $6 \mathrm{~h}$ ); reoxygenation was achieved by removing the plate from the hypoxic chamber and placing it into a normoxic incubator for a similar time course $(2 \mathrm{~h}, 4 \mathrm{~h}$ or $6 \mathrm{~h})$. Negative control referred to cells that were unstimulated by conditions of $\mathrm{H} / \mathrm{R}$ had also been designed in each group.

\section{Fluorescence microscopy}

After the H/R for $0 \mathrm{~h}, 2 \mathrm{~h}, 4 \mathrm{~h}$ or $6 \mathrm{~h}$, cells were fixed in 4\% paraformaldehyde (Sigma, USA, \#158127) for $10 \mathrm{~min}$ and mounted with FluorSave reagent (Merck Millipore Biosciences, Darmstadt, Germany, \#345789). eRFP-LC3 positive cells were observed using a fluorescence microscope (Olympus, Tokyo, Japan) and photographed.

\section{Transmission electron microscopy}

After the H/R treatment for $2 \mathrm{~h}, 4 \mathrm{~h}$ or $6 \mathrm{~h}$, cells were fixed with $2.5 \%$ glutaraldehyde at $4^{\circ} \mathrm{C}$ overnight and then fixed with $1 \%$ osmic acid. After being dehydrated with a graded series of ethanol (50\%, 70\%, 80\%, 95\%, 100\%, each $15 \mathrm{~min}$ ) and acetone (twice, each $15 \mathrm{~min}$ ), the cells were embedded by epoxide resin. The ultra-thin sections were made using an ultra-microtome (LKB-V, Bromma, Sweden), followed by staining with uranyl acetate and lead citrate. Then, sections were observed and photographed under a transmission electron microscope (H-600, Hitachi, Tokyo, Japan). 


\section{Cellular Physiology Cell Physiol Biochem 2017;41:79-90 \begin{tabular}{l|l|l} 
and Biochemistry Published 10.1159/000455953 & $\begin{array}{l}\text { C) } 2017 \text { The Author(s). Published by S. Karger AG, Basel } \\
\text { www.karger.com/cpb }\end{array}$
\end{tabular}}

Fan et al.: Autophagy Activation for Hypoxia Related Lung Diseases

Quantitative real-time PCR

Cells were respectively collected after the H/R treatment for $2 \mathrm{~h}, 4 \mathrm{~h}$ or $6 \mathrm{~h}$ for RNA extraction using Trizol reagent (Invitrogen, Carlsbad, CA, USA, \#15596-026). Five microgram of total RNA was reverse transcribed into complementary DNA (cDNA) using a cDNA synthesis kit (Fermentas, St. Leon-Rot, Germany, \#K1622) and PCR amplification was performed with the specified human primers: BIP, sense 5'-AGC CCA CCG TAA CAA TCA AG-3' and antisense, 5'-CCT GTC CCT TTG TCT TCA GC-3'; XBP-1, sense 5'-CCC ATG GAT TCT GAC GCT GT-3', and antisense 5'-ATG AGG TCC CCA CTG ACA GA-3'; CHOP, sense 5'-CAG CGC ATG AAG GAG AAG GA-3' and antisense 5'-ACA GGA GGT GAT GCC AAC AG-3'; $\beta$-actin, sense 5'-CAC GAT GGA GGG GCC GGA CTC ATC-3' and antisense 5'-TAA AGA CCT CTA TGC CAA CAC AGT-3'. The cycling conditions were as follows: $94^{\circ} \mathrm{C}$ for $4 \mathrm{~min}$ followed by 30 cycles of $94^{\circ} \mathrm{C}$ for $30 \mathrm{~s}, 57^{\circ} \mathrm{C}$ for $30 \mathrm{~s}$ and $72^{\circ} \mathrm{C}$ for $25 \mathrm{~s}$. The expression levels were normalized to $\beta$-actin.

\section{Immunohistochemistry}

Cell slides were made for the cells after H/R treatment for $2 \mathrm{~h}, 4 \mathrm{~h}$ or $6 \mathrm{~h}$. Then, cell slides were fixed in $4 \%$ paraformaldehyde for $15 \mathrm{~min}$ and washed with PBS $(\mathrm{pH}=7.4)$, followed by permeabilization with $0.5 \%$ Triton X-100 in PBS. In order to block the endogenous peroxidase activity, slides were transferred to $3 \%$ hydrogen peroxide and incubated for $15 \mathrm{~min}$ at room temperature. The slides were then incubated with primary antibodies specific for AMPK (Abcam, Cambridge, United Kingdom, \#Ab3759; 1:1000 dilution), Beclin-1 (Abcam, Cambridge, United Kingdom, \#Ab62472; 1:400 dilution), HDAC6 (Abcam, Cambridge, United Kingdom, \#Ab117516; 1:250 dilution) and p62 (Abcam, Cambridge, United Kingdom, \#Ab56416; 1:500 dilution) overnight at $4^{\circ} \mathrm{C}$. Slides were rinsed with PBS and incubated with appropriate horseradish peroxidase (HRP)-conjugated secondary antibodies for $20-30 \mathrm{~min}$ at $37^{\circ} \mathrm{C}$. The immunoreactions were visualized using diaminobenzidine (DAB, Dako, Carpinteria, CA, \#K3468) and slides were counterstained with Mayer's haematoxylin solution (Wako Pure Chemical Industries, Tokyo, Japan, \#131-09665). The stained slides were dehydrated and observed under a light microscope (E100, Nikon, Tokyo, Japan). Average values of integrated optical density (IOD) were obtained from three random fields per slide by using ImagePro Plus software (v5.0, Media Cybernetics, Bethesda, MD). Every data were detected three times at least.

\section{Western blot analysis}

Total proteins were respectively extracted from the cells undergoing the H/R treatment for $2 \mathrm{~h}, 4 \mathrm{~h}$ or $6 \mathrm{~h}$. Protein concentrations were determined using a bicinchoninic acid (BCA) protein assay kit (Biyuntian, Shanghai, China, \#P0010). Equal quantities of protein were electrophoresed on a 10\% sodium dodecyl sulfate polyacrylamide gel electrophoresis (SDS-PAGE) gel and transferred onto polyvinylidene fluoride (PVDF) membranes (Millipore, Bedford, MA, USA, \#IPVH00010). The membranes were blocked with 5\% fat-free milk for $2 \mathrm{~h}$ at room temperature and incubated overnight at $4{ }^{\circ} \mathrm{C}$ with the following rabbit primary antibodies: BIP (Santa Cruz, CA, USA, \#sc-33757; 1:200 dilution), XBP-1 (Santa Cruz, CA, USA, \#sc-7160; 1:200 dilution), CHOP (Santa Cruz, CA, USA, \#sc-575; 1:200 dilution), LC-3 (Cell Signaling Technology, Danvers, MA, \#2775; 1:1000 dilution), AMPK (Bioworld, St. Louis Park, MN, USA, \#BS5503; 1:600 dilution), Beclin-1 (Santa Cruz, CA, USA, \#sc-11427; 1:200 dilution), HDAC6 (Santa Cruz, CA, USA, \#sc-5258; 1:200 dilution) and p62 (Santa Cruz, CA, USA, \#sc-8314; 1:400 dilution). Horseradish peroxidase (HRP)conjugated secondary antibodies (Boster, Wuhan, China, \#BA1060; 1:50000) were then incubated with the membranes for $2 \mathrm{~h}$ at $37^{\circ} \mathrm{C}$. The formed immunocomplex was visualized by enhanced chemiluminescence reagent (ECL, Thermo Scientific, Waltham, MA, USA, \#NCI5079) and exposed to X-ray films (Kodak Insight film, Eastman Kodak Company, Rochester, NY, \#XBT-1). The images were quantified by BandScan software (v 5.0, Glyko, Novato, USA) and band intensities were expressed relative to $\beta$-actin.

\section{Statistical analysis}

The data were expressed as mean \pm standard deviation (SD). Comparisons between groups were performed using one-way analysis of variance (ANOVA), followed by Student's t-test. Statistical analysis was performed using the SPSS version 18.0 software (Chicago, IL, USA) and $P<0.05$ was considered to be statistically significant. 


\section{Cellular Physiology

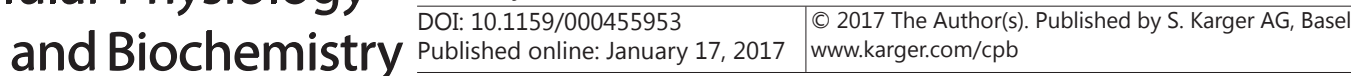 \\ Fan et al.: Autophagy Activation for Hypoxia Related Lung Diseases}

\section{Results}

Cytotoxicity assay of 3-MA and Rap

According to the MTT assay, autophagy-stimulating agent Rap significantly decreased cell viability at the dose of $250 \mathrm{nM}(0.73 \pm 0.23)$, compared with $150 \mathrm{nM}(0.35 \pm 0.34)$ and $200 \mathrm{nM}$ dose $(0.12 \pm 0.38)$, while autophagy inhibitor 3-MA significantly improved the cell viability at the concentration of $5 \mathrm{mM}$ with the inhibition rate of $19.77 \pm 0.08 \%$ in comparison with $10 \mathrm{mM}(20.56 \pm 0.12)$ and $15 \mathrm{mM}(49.14 \pm 0.08)$ dose. Therefore, we consider the 250 nM Rap or $5 \mathrm{mM} 3$-MA may be the optimal concentration for clearance or induction of ER stress cells before the $\mathrm{H} / \mathrm{R}$ treatment.

\section{Effect of 3-MA and Rap on autophagy formation after $H / R$}

To determine if 3-MA and Rap increased or decreased levels of autophagy, eRFP-LC3 positive cells were preliminarily monitored under fluorescence microscopy because LC3 is the universal marker of autophagic vacuole. As shown in Fig. 1A, the red fluorescent dots were gradually increased along with the treatment time of H/R and the eRFP-LC3 dot was obviously more in cells incubated with Rap than those of the control and cells incubated with 3-MA.

Fig. 1. Rapamycin (Rap) induced, but 3 -methyla denine (3-MA) inhibited autophagy in alveolar epithelial cells. A, eRFP-LC3 expression in cells incubated with $250 \mathrm{nM}$ Rap or 5 mM 3-MA before the hypoxiareoxygenation treatment for $2 \mathrm{~h}, 4 \mathrm{~h}$ or 6 h. B, LC3 protein expression by western blot. C, quantitative results of western blot. ${ }^{*} P<0.05$, compared with the control cells; \# $P<0.05$, compared with the cells treated with Rap.

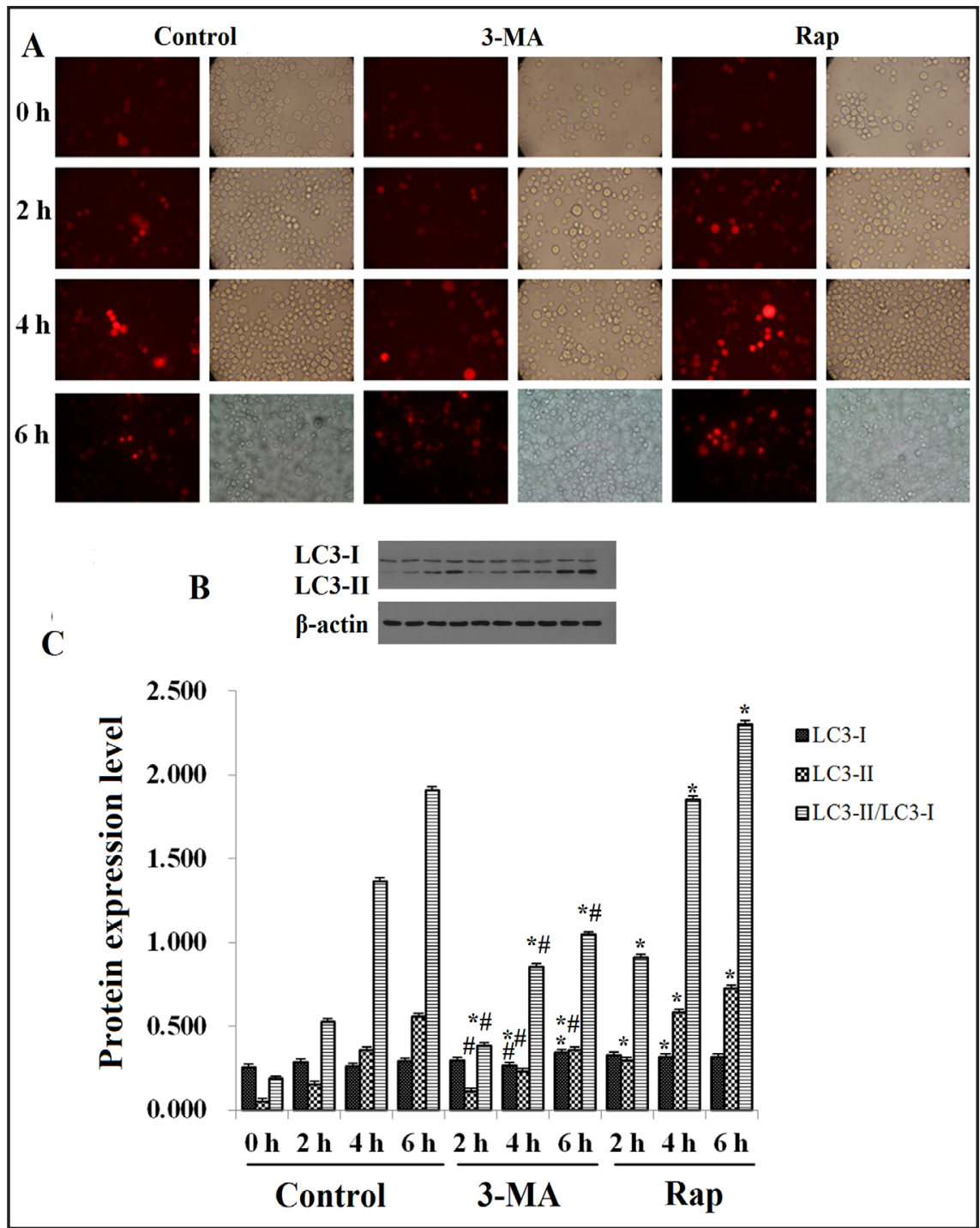




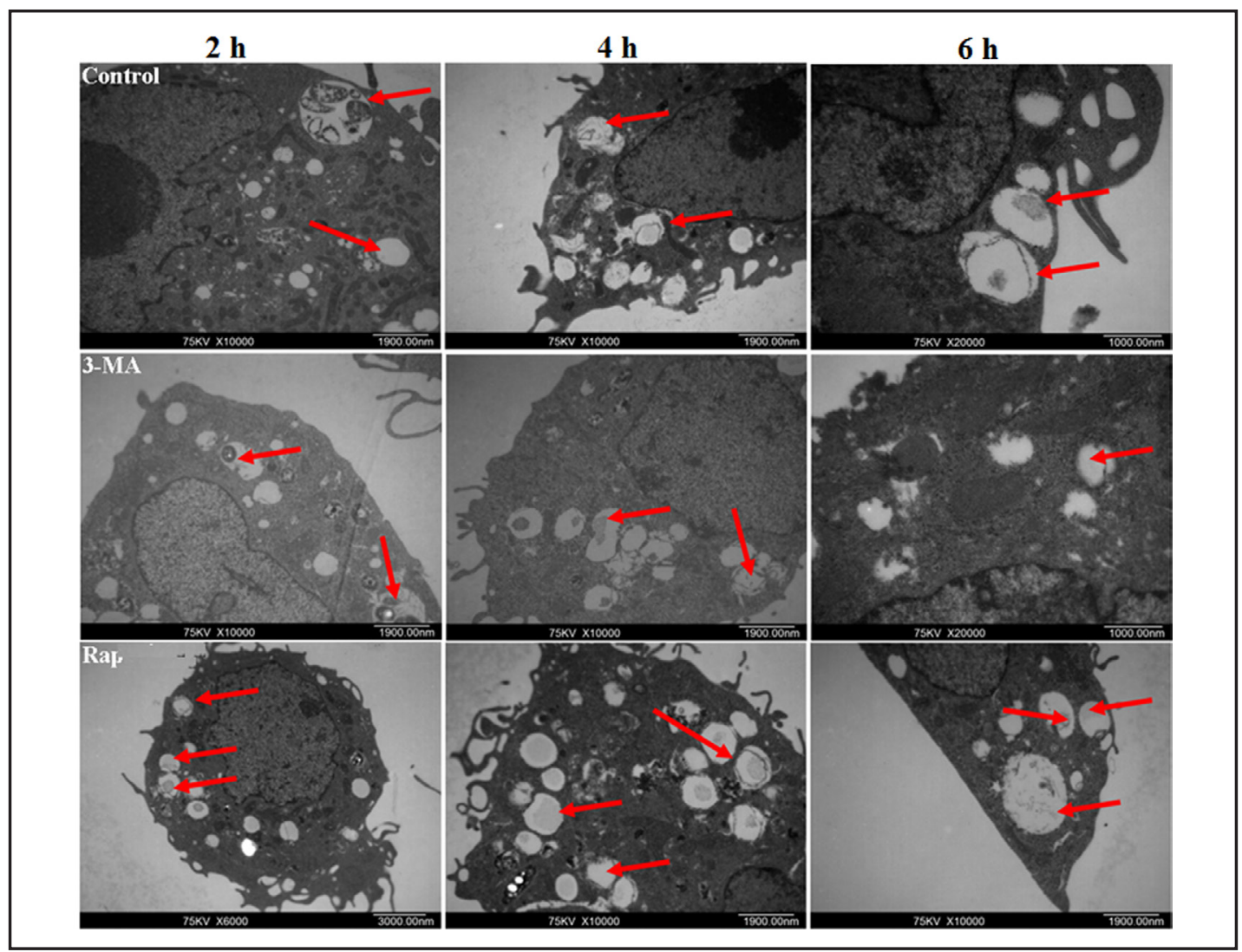

Fig. 2. The changes of autophagic morphology for cells incubated with $250 \mathrm{nM}$ Rap or $5 \mathrm{mM} 3$-MA before the hypoxia-reoxygenation treatment for $2 \mathrm{~h}, 4 \mathrm{~h}$ or $6 \mathrm{~h}$ observed by a transmission electron microscope. The red arrows represent the autophagosomes.

Fig. 3. The mRNA expression levels of BIP, XBP-1 and CHOP in cells incubated with 250 nM Rap or 5 mM 3-MA before the hypoxia-reoxygenation treatment for $2 \mathrm{~h}, 4 \mathrm{~h}$ or $6 \mathrm{~h}$. The expression levels were normalized to $\beta$-actin. ${ }^{*} P<0.05$, compared with the control cells; \# $P<$ 0.05 , compared with the cells treated with Rap.

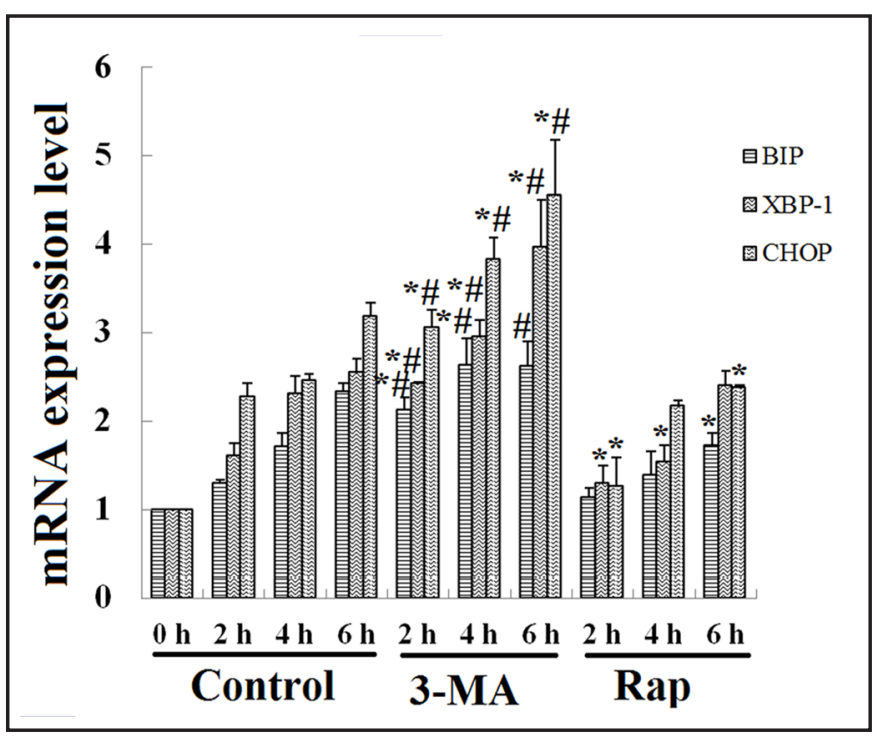

To further confirm the autophagic activity, the LC3-I (16 kDa) to LC3-II (14 kDa) conversion [20-23] was checked through western blot analysis. As expected, Rap treatment induced a significant increase of LC3-II/LC3-I ratio in cells as compared with control and cells treated with $3-\mathrm{MA}$ at any duration $(P<0.05$; Fig. 1B).

Furthermore, the autophagosome accumulation was also detected by using transmission electron microscopy. Consistent with the increased eRFP-LC3 dot formation, autophagosomes 
Fig. 4. The protein expression levels of BIP, XBP-1 and CHOP in cells incubated with $250 \mathrm{nM}$ Rap or $5 \mathrm{mM}$ 3-MA before the hypoxia-reoxygenation treatment for $2 \mathrm{~h}, 4 \mathrm{~h}$ or $6 \mathrm{~h}$. A, western blot analysis; $\mathrm{B}$, quantitative results. $* P<0.05$, compared with the control cells; \# $P<0.05$, compared with the cells treated with Rap.

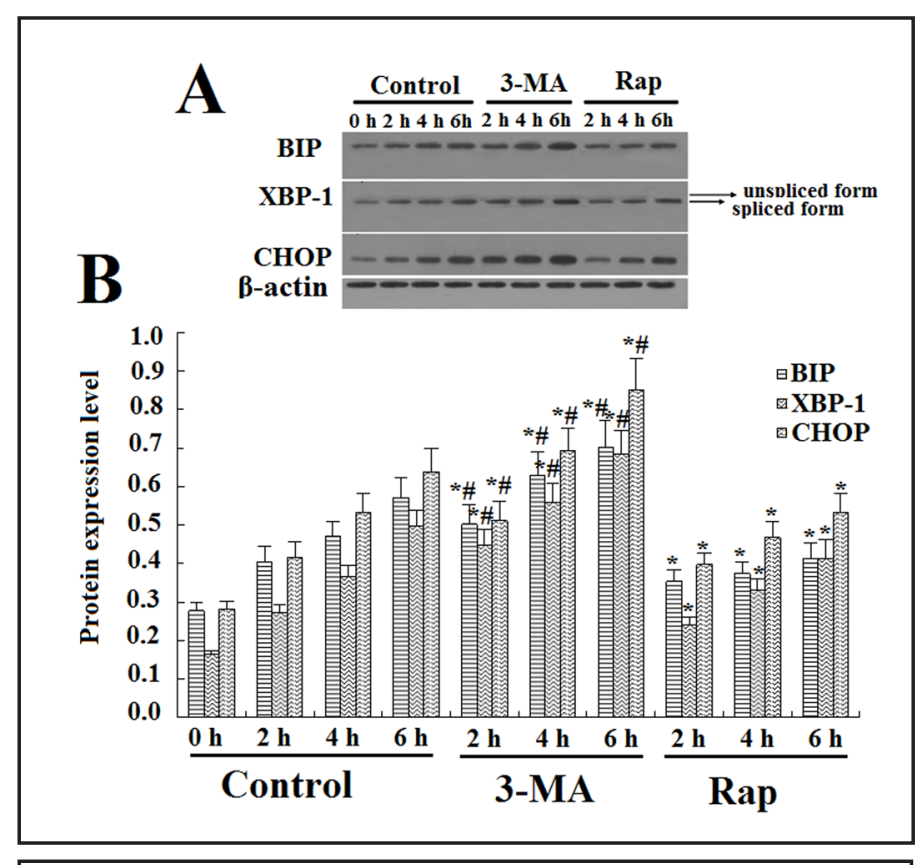

Fig. 5. Immunohistochemistry analysis of the protein expressions of AMPK, Beclin-1, HDAC6 and p62 in cells incubated with 250 nM Rap or $5 \mathrm{mM}$ 3-MA before the hypoxia-reoxygenation treatment for $2 \mathrm{~h}$, 4 h or 6 h. $* P<0.05$, compared with the control cells; \# $P<0.05$, compared with the cells treated with Rap.

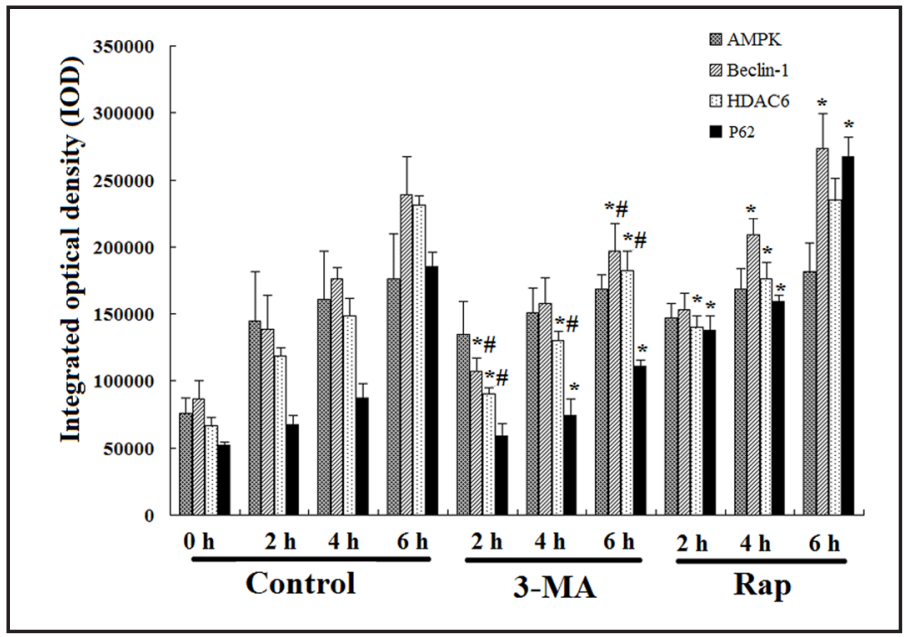

was also more frequently observed in Rap treated cells compared with control and 3-MA group (Fig. 2) and became larger along with the extension of treatment time. Collectively, these results demonstrated that Rap induced more autophagosome formation before H/R.

The relationship between autophagy formation and ER stress after $H / R$

To demonstrate whether the autophagy induction or clearance prior to $H / R$ may influence the ER stress, we detected the expressions of UPR genes (BIP, XBP-1 and CHOP) which were used to indicate the ER stress. As shown in Fig. 3, there was a rising tendency in the mRNA expression levels of BIP, XBP-1 and CHOP in control cells along with the increasing of $H / R$ treatment duration. Prior to $H / R$, cells treated with 3-MA further increased, but Rap treatment decreased their expressions $(P<0.05)$. This conclusion was also confirmed by investigating the protein expressions of BIP, XBP-1 and CHOP using western blot (Fig. 4).

Moreover, the expression levels of autophagy related genes (AMPK, Beclin-1, HDAC6 and p62) were also explored by immunohistochemistry and western blot to observe whether there was a negative relationship between autophagy and UPR genes as previously indicated. By integrating the results of two methods, we consider the protein expressions of Beclin-1, HDAC6 and p62 were significantly higher in cells treated with Rap, but significantly lower in cells treated with 3-MA, compared with the control cells especially after H/R for 
Fig. 6. Western blot analysis of AMPK, Beclin-1, HDAC6 and p62 in cells incubated with $250 \mathrm{nM}$ Rap or 5 mM 3-MA before the hypoxia-reoxygenation treatment for $2 \mathrm{~h}, 4 \mathrm{~h}$ or $6 \mathrm{~h}$. A, western blot results; $\mathrm{B}$, quantitative results. * $P<0.05$, compared with the control cells; \# $P<0.05$, compared with the cells treated with Rap.

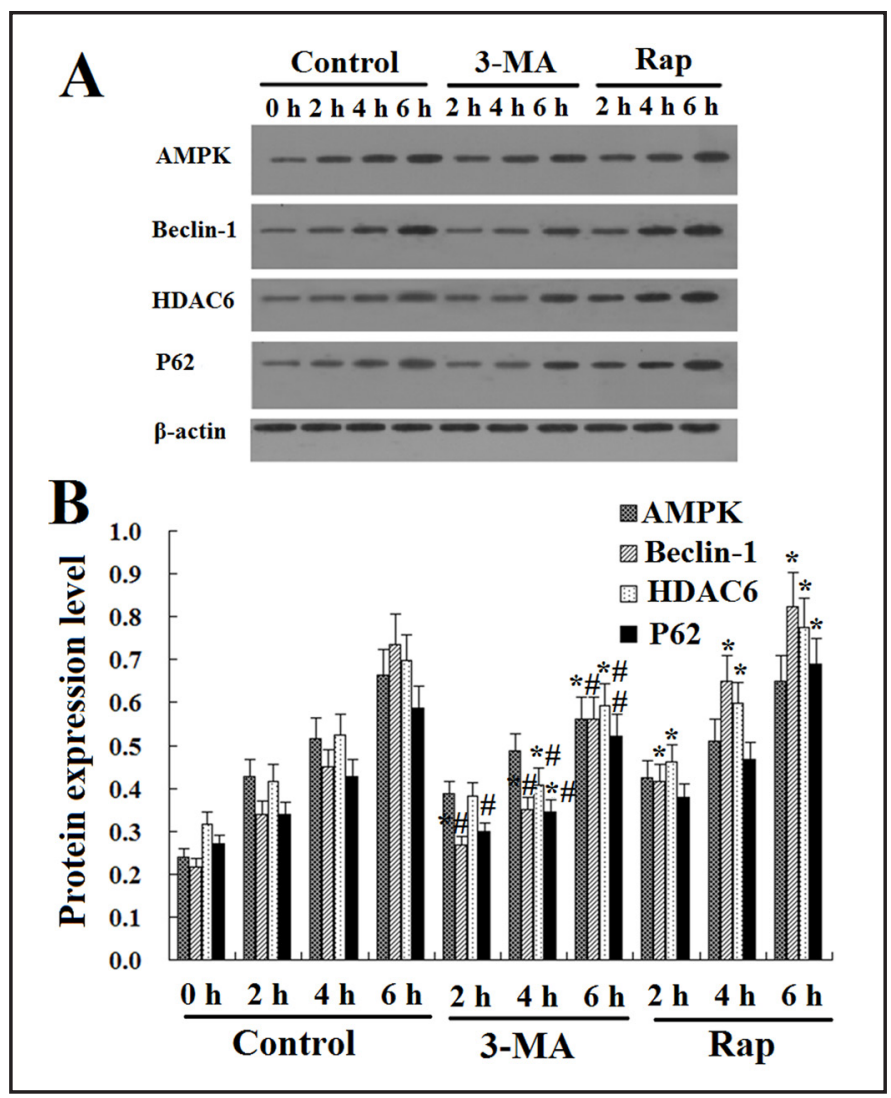

$6 \mathrm{~h}$. However, there was no obvious difference in protein expression of AMPK among three groups (Fig. 5 and Fig. 6). Collectively, these results demonstrated that Rap induced more autophagy related genes which may feedback inhibit the UPR genes expression and thus relieve the lung cell injury.

\section{Discussion}

Previous studies demonstrated that the activity of autophagy can be increased in hypoxia related lung diseases, [24] insufficient autophagy promotes lung cell senescence [25] and administration of drug that enhances the autophagic activity can prevent the development of hypoxia related lung diseases [25-27]. However, no study has been performed to investigate the protective effects of autophagy activation for alveolar epithelial cells against H/R induced injuries. In our study, we, for the first time, used the time course analyses to demonstrate that: (1) autophagy is activated in response to ER stress in alveolar epithelial cells undergoing H/R treatment; (2) pharmacological agent Rap added prior to $\mathrm{H} / \mathrm{R}$ ameliorates cellular ER stress with the decreased expressions of BIP, XBP- 1 and CHOP via stimulating more autophagosome accumulation and expressions of autophagy genes LC3 and Beclin- 1 . These results seemed to be in accordance with the studies of $H / R$ induced brain, myocardial and kidney injuries $[14,15,17,28]$.

Rap is a commonly used inhibitor for mammalian target of rapamycin (mTOR). Recent study suggests AMPK is a positive regulator of autophagy mainly by suppressing the mammalian target of rapamycin (mTOR) complex and phosphorylating unc-51-like kinase 1 (ULK1, the ortholog of Atg1 in mammals) at Ser 317 and Ser 777 [29]. Further studies indicate that Rap can upregulate autophagy by activation of AMPK followed by resulting in the inhibition of mTOR-ULK1 activity [30,31]. Accordingly, we believe AMPK pathway may be an important mechanism by which Rap induced autophagy. Therefore, we also detected 
whether the expression of AMPK was increased after Rap treatment, but decreased by 3-MA. Unfortunately, no significant difference in AMPK was observed among groups, indicating the other pathways (such as PI3k/Akt pathway [28] and ERK pathway [32]) by which Rap induced autophagy in alveolar epithelial cells may be involved and further studies are still needed to confirm.

HDAC6 is the first identified microtubule-associated deacetylase that associates with autophagy. One the one hand, it binds with both the polyubiquitinated misfolded proteins and dynein motors via corresponding domains, thereby facilitating the transportation of ubiquitinated misfolded proteins and formation of an aggresome; [33] one the other hand, it stimulates autophagosome-lysosome fusion through recruiting a cortactin-dependent, actinremodeling machinery followed by degrading the misfolded proteins via autophagy [34]. Deficiency in HDAC6 reduces this transportation of autophagosomes and leads to decreased aggresome-autophagic clearance of abnormal proteins [35]. Recent studies investigating the relationship between HDAC6 and autophagy are associated with the neurodegeneration $[36,37]$. Few reports are seen in lung diseases. As expected, the expression of HDAC6 was significantly increased after $\mathrm{H} / \mathrm{R}$, especially Rap treatment.

P62 is also an ubiquitin-binding protein and thus participates in the formation of ubiquitinylated protein aggregates similarly. But, unlike with HDAC6, p62 itself is able to be translocated to the autophagosome via interacting with the central component of the autophagy machinery LC3 and then degraded [38]. Therefore, the level of p62 is usually considered to be negatively correlated with the autophagic activity [17]. However, a recent study indicated that the expressions of p62, ubiquitinated proteins, and LC3-II were significantly induced in neuronal cells under hypoxic stress [39]. Depletion of p62 significantly exacerbated, but overexpression of p62 protected against the neuropathological injuries [40]. In line with these studies, our study also found p62 was significantly higher expressed after H/R, especially Rap treatment, but decreased under 3-MA treatment. We believe this phenomenon may be attributed to the fact that p62 may be needed to be compensatorily synthesized using the autophagy-derived amino acids to confirm the persistent proceeding of the autophagy process [41]. Thus, the autophagy activation by rap needs more p62, but 3-MA needs lower p62. In addition, p62 may be also involved in other pathways. For example, activation of $\mathrm{p} 62$ /Keap1/Nrf2 stress defence pathway by H/R may also contribute to the high expression of p62. By competitively binding to Keap1, p62 induces the release of free transcription factor Nrf2 which promotes the transcriptional upregulation and synthesis of antioxidant targets, including p62 itself [42]. Chronic treatment with Rap is also demonstrated to significantly upregulate Nrf2 and p62, but downregulate Keap1 to protect cells from exogenous ROS exposure [43]. In brief, the increased expression of p62 in alveolar epithelial cells after H/R, especially Rap treatment may be explained by a high synthesis/ degradation ratio of p62. This also indicates it should be cautious to use p62 as an indicator of autophagy flux with caution and the level of p62 mRNA should be simultaneously measured along with the p62 protein level $[41,44]$.

Although our study may preliminarily imply the beneficial effects for reduction of the UPR response and alleviation of H/R induced ER stress by the use of autophagy agonist Rap before $H / R$, more attention should be paid that there may be dual functions of up-regulation of autophagy to both protect and cause death of cells indicated by some studies $[45,46]$. We believe the function of autophagy in H/R depends on the exposure conditions (such as time) and might, likewise, differ between cell or disease types. Therefore, further studies are necessary to confirm our conclusion by in vivo study with longer time of hypoxia or reoxygenation.

In summary, our study findings are consistent with the possibility that activation of autophagy may be potentially beneficial for alleviation of H/R induced ER stress and lung injuries. Rap or other autophagy activators can be promising agents before mechanical ventilation or reperfusion to prevent re-damage to the pulmonary function in hypoxia related lung diseases, such as COPD. 


\section{Cellular Physiology Cell Physiol Biochem 2017;41:79-90 \begin{tabular}{ll|l} 
and Biochemistry Published onlIne: January 17, 2017 & $\begin{array}{l}\text { (C) } 2017 \text { The Author(s). Published by S. Karger AG, Basel } \\
\text { www.karger.com/cpb }\end{array}$ \\
\hline
\end{tabular}}

Fan et al.: Autophagy Activation for Hypoxia Related Lung Diseases

\section{Acknowledgments}

This project was supported by the National Natural Science Foundation (General project) of China (No. 81170076).

\section{Disclosure Statement}

None.

\section{References}

1 Zhou G, Dada LA, Sznajder JI: Regulation of alveolar epithelial function by hypoxia. Eur Respir J 2008;31:1107-1113.

2 Grek CL, Newton DA, Spyropoulos DD, Baatz JE: Hypoxia up-regulates expression of hemoglobin in alveolar epithelial cells. Am J Respir Cell Mol Biol 2011;44:439-447.

-3 Wurnig MC, Tsushima Y, Weiger M, Jungraithmayr W, Boss A: Assessing lung transplantation ischemiareperfusion injury by microcomputed tomography and ultrashort echo-time magnetic resonance imaging in a mouse model. Invest Radiol 2014;49:23-28.

4 Li C, Jackson RM: Reactive species mechanisms of cellular hypoxia-reoxygenation injury. Am J Physiol Cell Physiol 2002;282:C227-C241.

-5 Ferrari RS, Andrade CF: Oxidative stress and lung ischemia-reperfusion injury. Oxid Med Cell Longev 2015;2015:590987.

6 Bhandary B, Marahatta A, Kim HR, Chae HJ: An involvement of oxidative stress in endoplasmic reticulum stress and its associated diseases. Int J Mol Sci 2012;14:434-456.

7 De Franceschi L, Malpeli G, Scarpa A, Janin A, Muchitsch EM, Roncada P, Leboeuf C, Corrocher R, Beuzard Y, Brugnara C: Protective effects of s-nitrosoalbumin on lung injury induced by hypoxia-reoxygenation in mouse model of sickle cell disease. Am J Physiol Lung Cell Mol Physiol 2006;291:L457-L465.

8 Tarras SL, Diebel LN, Liberati DM, Ginnebaugh K: Pharmacologic stimulation of the nicotinic antiinflammatory pathway modulates gut and lung injury after hypoxia-reoxygenation injury. Surgery 2013;154: 841-847; discussion 847-848.

-9 Deegan S, Saveljeva S, Gorman AM, Samali A: Stress-induced self-cannibalism: On the regulation of autophagy by endoplasmic reticulum stress. Cell Mol Life Sci 2013;70:2425-2441.

10 Cheng Y, Yang JM: Survival and death of endoplasmic-reticulum-stressed cells: Role of autophagy. World J Biol Chem 2011;2:226-231.

-11 Rouschop KM, van den Beucken T, Dubois L, Niessen H, Bussink J, Savelkouls K, Keulers T, Mujcic H, Landuyt W, Voncken JW, Lambin P, van der Kogel AJ, Koritzinsky M, Wouters BG: The unfolded protein response protects human tumor cells during hypoxia through regulation of the autophagy genes MAP1LC3B and ATG5. J Clin Invest 2010;120:127-141.

-12 Li J, Ni M, Lee B, Barron E, Hinton DR, Lee AS: The unfolded protein response regulator grp78/bip is required for endoplasmic reticulum integrity and stress-induced autophagy in mammalian cells. Cell Death Differ 2008;15:1460-1471.

-13 Suh DH, Kim MK, Kim HS, Chung HH, Song YS: Unfolded protein response to autophagy as a promising druggable target for anticancer therapy. Ann N Y Acad Sci 2012;1271:20-32.

14 Sheng R, Liu XQ Zhang LS, Gao B, Han R, Wu YQ, Zhang XY, Qin ZH: Autophagy regulates endoplasmic reticulum stress in ischemic preconditioning. Autophagy 2012;8:310-325.

-15 Carloni S, Albertini MC, Galluzzi L, Buonocore G, Proietti F, Balduini W: Increased autophagy reduces endoplasmic reticulum stress after neonatal hypoxia-ischemia: Role of protein synthesis and autophagic pathways. Exp Neurol 2014;255:103-112.

16 Fang L, Li X, Luo Y, He W, Dai C, Yang J: Autophagy inhibition induces podocyte apoptosis by activating the pro-apoptotic pathway of endoplasmic reticulum stress. Exp Cell Res 2014;322:290-301. 


\section{Cellular Physiology Cell Physiol Biochem 2017;41:79-90 and Biochemistry DOI: 10.1159/000455953 \begin{tabular}{l|l} 
Po 2017 The Author(s). Published by S. Karger AG, Basel \\
www.kargercom/cpb
\end{tabular}

Fan et al.: Autophagy Activation for Hypoxia Related Lung Diseases

17 Guan X, Qian Y, Shen Y, Zhang L, Du Y, Dai H, Qian J, Yan Y: Autophagy protects renal tubular cells against ischemia / reperfusion injury in a time-dependent manner. Cell Physiol Biochem 2015;36:285-298.

18 Douglas WH, Kaighn ME: Clonal isolation of differentiated rat lung cells. In Vitro 1974;10:230-237.

19 Farivar AS, Mackinnon-Patterson BC, Barnes AD, McCourtie AS, Mulligan MS: Cyclosporine modulates the response to hypoxia-reoxygenation in pulmonary artery endothelial cells. Ann Thorac Surg 2005;79:10101016.

20 Xiao J, Zhu X, Kang B, Xu J, Wu L, Hong J, Zhang Y, Ni X, Wang Z: Hydrogen sulfide attenuates myocardial hypoxia-reoxygenation injury by inhibiting autophagy via mTOR activation. Cell Physiol Biochem 2015;37:2444-2453.

21 Wang XM, Yang YJ, Wu YJ, Zhang Q, Qian HY: Attenuating hypoxia-induced apoptosis and autophagy of mesenchymal stem cells: the potential of sitagliptin in stem cell-based therapy. Cell Physiol Biochem 2015;37:1914-1926.

22 Zhang F, Wang J, Chu J, Yang C, Xiao H, Zhao C, Sun Z, Gao X, Chen G, Han Z, Zou W, Liu T: MicroRNA-146a induced by hypoxia promotes chondrocyte autophagy through Bcl-2. Cell Physiol Biochem 2015;37:14421453.

-23 Hsieh DJ, Kuo WW, Lai YP, Shibu MA, Shen CY, Pai P, Yeh YL, Lin JY, Viswanadha VP, Huang CY: 17 $\beta$-estradiol and/or estrogen receptor $\beta$ attenuate the autophagic and apoptotic effects induced by prolonged hypoxia through HIF-1 $\alpha$-mediated BNIP3 and IGFBP-3 signaling blockage. Cell Physiol Biochem 2015;36:274-284.

24 Mizumura K, Cloonan SM, Haspel JA, Choi AM: The emerging importance of autophagy in pulmonary diseases. Chest 2012;142:1289-1299.

25 Fujii S, Hara H, Araya J, Takasaka N, Kojima J, Ito S, Minagawa S, Yumino Y, Ishikawa T, Numata T, Kawaishi M, Hirano J, Odaka M, Morikawa T, Nishimura S, Nakayama K, Kuwano K: Insufficient autophagy promotes bronchial epithelial cell senescence in chronic obstructive pulmonary disease. Oncoimmunology 2012;1:630-641.

-26 Yen YT, Yang HR, Lo HC, Hsieh YC, Tsai SC, Hong CW, Hsieh CH: Enhancing autophagy with activated protein c and rapamycin protects against sepsis-induced acute lung injury. Surgery 2013;153:689-698.

27 Liu H, Mi S, Li Z, Lv X, Li K, Hua F, Hu Z: Sb216763, a selective small molecule inhibitor of glycogen synthase kinase-3, improves bleomycin-induced pulmonary fibrosis via activating autophagy. Acta Pharm Sin B 2013;3:226-233.

28 Wang LQ Cheng XS, Huang CH, Huang B, Liang Q: Rapamycin protects cardiomyocytes against anoxia/ reoxygenation injury by inducing autophagy through the pi3k/akt pathway. J Huazhong Univ Sci Technolog Med Sci 2015;35:10-15.

29 Kim J, Kundu M, Viollet B, Guan KL: AMPK and mTOR regulate autophagy through direct phosphorylation of Ulk1. Nat Cell Biol 2011;13:132-141.

30 Habib SL: Mechanism of activation of AMPK and upregulation of OGG1 by rapamycin in cancer cells. Oncotarget 2011;2:958-959.

-31 Wu L, Feng Z, Cui S, Hou K, Tang L, Zhou J, Cai G, Xie Y, Hong Q Fu B, Chen X: Rapamycin upregulates autophagy by inhibiting the mTOR-ULK1 pathway, resulting in reduced podocyte injury. PLoS One 2013;8:e63799.

-32 Wu J, Niu J, Li X, Li Y, Wang X, Lin J, Zhang F. Hypoxia induces autophagy of bone marrow-derived mesenchymal stem cells via activation of ERK1/2. Cell Physiol Biochem 2014;33:1467-1474.

-33 Kawaguchi Y, Kovacs JJ, McLaurin A, Vance JM, Ito A, Yao TP: The deacetylase hdac6 regulates aggresome formation and cell viability in response to misfolded protein stress. Cell 2003;115:727-738.

-34 Yan J: Interplay between hdac6 and its interacting partners: Essential roles in the aggresome-autophagy pathway and neurodegenerative diseases. DNA Cell Biol 2014;33:567-580.

-35 Lee JY, Koga H, Kawaguchi Y, Tang W, Wong E, Gao YS, Pandey UB, Kaushik S, Tresse E, Lu J, Taylor JP, Cuervo AM, Yao TP: HDAC6 controls autophagosome maturation essential for ubiquitin-selective quality-control autophagy. EMBO J 2010;29:969-980.

-36 Pandey UB, Batlevi Y, Baehrecke EH, Taylor JP: HDAC6 at the intersection of autophagy, the ubiquitinproteasome system, and neurodegeneration. Autophagy 2007;3:643-645.

-37 Pandey UB, Nie Z, Batlevi Y, McCray BA, Ritson GP, Nedelsky NB, Schwartz SL, DiProspero NA, Knight MA, Schuldiner O, Padmanabhan R, Hild M, Berry DL, Garza D, Hubbert CC, Yao TP, Baehrecke EH, Taylor JP: HDAC6 rescues neurodegeneration and provides an essential link between autophagy and the UPS. Nature 2007;447:859-863. 


\section{Cellular Physiology Cell Physiol Biochem 2017;41:79-90

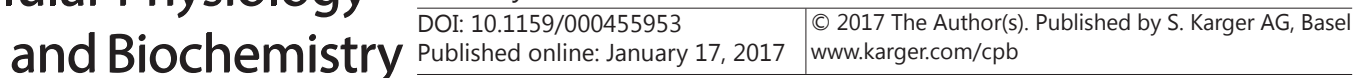

-38 Lippai M, Low P: The role of the selective adaptor p62 and ubiquitin-like proteins in autophagy. Biomed Res Int 2014;2014:832704.

- 39 Tanabe F, Yone K, Kawabata N, Sakakima H, Matsuda F, Ishidou Y, Maeda S, Abematsu M, Komiya S, Setoguchi T: Accumulation of p62 in degenerated spinal cord under chronic mechanical compression: Functional analysis of p62 and autophagy in hypoxic neuronal cells. Autophagy 2011;7:1462-1471.

-40 Doi H, Adachi H, Katsuno M, Minamiyama M, Matsumoto S, Kondo N, Miyazaki Y, Iida M, Tohnai G, Qiang Q, Tanaka F, Yanagawa T, Warabi E, Ishii T, Sobue G: P62/SQSTM1 differentially removes the toxic mutant androgen receptor via autophagy and inclusion formation in a spinal and bulbar muscular atrophy mouse model. J Neurosci 2013;33:7710-7727.

41 Sahani MH, Itakura E, Mizushima N: Expression of the autophagy substrate SQSTM1/p62 is restored during prolonged starvation depending on transcriptional upregulation and autophagy-derived amino acids. Autophagy 2014;10:431-441.

-42 Jain A, Lamark T, Sjøttem E, Larsen KB, Awuh JA, Øvervatn A, Mcmahon M, Hayes JD, Johansen T: P62/ SQSTM1 is a target gene for transcription factor nrf2 and creates a positive feedback loop by inducing antioxidant response element-driven gene transcription. J Biol Chem 2010;285:22576-22591.

-43 Lerner C, Bitto A, Pulliam D, Nacarelli T, Konigsberg M, Remmen HV, Torres C, Sell C: Reduced mammalian target of rapamycin activity facilitates mitochondrial retrograde signaling and increases lifespan in normal human fibroblasts. Aging Cell 2013;12:966-977.

-44 Gomez-Sanchez R, Pizarro-Estrella E, Yakhine-Diop SM, Rodriguez-Arribas M, Bravo-San Pedro JM, Fuentes JM, Gonzalez-Polo RA: Routine western blot to check autophagic flux: Cautions and recommendations. Anal Biochem 2015;477:13-20.

45 Bristol ML, Di X, Beckman MJ, Wilson EN, Henderson SC, Maiti A, Fan Z, Gewirtz DA: Dual functions of autophagy in the response of breast tumor cells to radiation: Cytoprotective autophagy with radiation alone and cytotoxic autophagy in radiosensitization by vitamin D3. Autophagy 2012;8:739-753.

46 Chang J, Wang W, Zhang H, Hu Y, Wang M, Yin Z: The dual role of autophagy in chondrocyte responses in the pathogenesis of articular cartilage degeneration in osteoarthritis. Int J Mol Med 2013;32:1311-1318. 